\title{
Improving the writing skills of college students
}

\author{
Ronald T. Kellogg ANd BASCOM A. RAUlerson III \\ Saint Louis University, St. Louis, Missouri
}

\begin{abstract}
Advanced writing skills are an important aspect of academic performance as well as of subsequent workrelated performance. However, American students rarely attain advanced scores on assessments of writing skills (National Assessment of Educational Progress, 2002). In order to achieve higher levels of writing performance, the working memory demands of writing processes should be reduced so that executive attention is free to coordinate interactions among them. This can in theory be achieved through deliberate practice that trains writers to develop executive control through repeated opportunities to write and through timely and relevant feedback. Automated essay scoring software may offer a way to alleviate the intensive grading demands placed on instructors and, thereby, substantially increase the amount of writing practice that students receive.
\end{abstract}

Effective writing skills are central both in higher education and the world of work that follows. One's ability to compose an extended text is the single best predictor of success in course work during the freshman year (Geiser \& Studley, 2001). Gains in informative and analytical writing ability are, moreover, taken as a good indicator of the value added by higher education (Benjamin \& Chun, 2003). Finally, a large share of the value added by businesses in a knowledge-based economy is codified in written documents, placing a premium on a literate workforce (Brandt, 2005).

Despite the importance of writing skills, the National Assessment of Educational Progress (NAEP, 2002) has painted a dismal picture of the writing preparedness of American students. Less than a third of students in 4 th grade $(28 \%)$, 8 th grade $(31 \%)$, and 12 th grade $(21 \%)$ scored at or above proficient levels. Only $2 \%$ wrote at an advanced level for all three samples. Although writing scores had reliably improved for 4th and 8th graders since the 1998 testing, they decreased slightly for 12 th graders.

Writing well is a major cognitive challenge, because it is at once a test of memory, language, and thinking ability. It demands rapid retrieval of domain-specific knowledge about the topic from long-term memory (Kellogg, 2001). A high degree of verbal ability is necessary to generate cohesive text that clearly expresses the ideational content (McCutchen, 1984). Writing ability further depends on the ability to think clearly about substantive matters (Nickerson, Perkins, \& Smith, 1985).

Finally, working memory is severely taxed by the production of extended texts. Representations of the author's intended ideas, the meaning of the text as it is written, and even the possible meanings of the text as construed by the imagined readers need to be transiently maintained during text production (Traxler \& Gernsbacher, 1992). Moreover, mature writers concurrently juggle the plan- ning of ideas, the generation of text, and the reviewing of ideas and text, placing heavy demands on executive attention (Hayes \& Flower, 1980; Kellogg, 1996). Given these demands, it is not surprising that both developmental and individual differences in writing ability can be explained in terms of the limitations of working memory (McCutchen, 1996). One must have the capacity to maintain multiple representations and to control the interactions among planning, generation, and reviewing in order to write well.

Cognitive science has focused more on numeracy and the reading side of literacy than on writing (Levy, 1997). Even so, several findings have implications for the design of writing instruction, as noted in previous reviews of the literature (Hayes \& Flower, 1986; Rijlaarsdam et al., 2005). Our focus here is on a principle found useful in training complex skills but relatively overlooked to date in the field of written composition. Deliberate practice has been proven highly effective in training performance on related tasks, such as typing (one motor output for writing), chess (another planning-intensive task), and music (another creative production task). The very best violinists, for example, have accumulated more than $10,000 \mathrm{~h}$ in solitary practice, whereas lesser experts $(7,500 \mathrm{~h})$, least accomplished experts $(5,000 \mathrm{~h})$, and amateurs $(1,500 \mathrm{~h})$ have devoted proportionately less time to selfimprovement (K. A. Ericsson, Krampe, \& Tesch-Römer, 1993). We suggest that deliberate practice theoretically offers a too infrequently exploited means to attain the working memory control required in writing.

In what follows, we first briefly review some facts on the importance of cognitive control in writing skill. We then present the elements of deliberate practice in the training of college-level writers and evidence of their importance. Finally, we discuss difficulties in implementing deliberate practice in writing instruction.

R. T. Kellogg, kelloggr@slu.edu 


\section{Cognitive Control in Writing}

Composing an extended text appears to require the selfregulation of planning, text generation, and reviewing through metacognitive control of these processes (Graham \& Harris, 2000; Zimmerman \& Risemberg, 1997). All three basic processes require executive attention, in addition to maintaining representations in the verbal, visual, and spatial stores of working memory (Kellogg, Olive, \& Piolat, 2007). Mature writing requires numerous transitions among planning, generation, and reviewing (Hayes \& Flower, 1980; Levy \& Ransdell, 1995), as the author attempts to solve the content problem of what to say and the rhetorical problem of how to say it (Bereiter \& Scardamalia, 1987; Scardamalia \& Bereiter, 1991). Three facts indicate that self-regulatory control of written production depends on having adequate working memory resources.

First, measures of working memory capacity correlate with writing performance (Ransdell \& Levy, 1996). This is but one instance of a wide range of complex cognitive tasks, including tests of fluid intelligence, that are uniquely predicted by one's ability to control processing through executive attention (Engle, Tuholski, Laughlin, \& Conway, 1999). Neuroimaging of the frontal lobe regions linked to executive attention in working memory also reveal greater activation in individuals with high fluid $g$ than in those with low fluid $g$ (Duncan et al., 2000). Converging experimental results show that distracting executive attention with a concurrent task disrupts both the quality and fluency of text composition (Ransdell, Levy, \& Kellogg, 2002).

Second, children's fluency in generating written text is limited until they master the mechanical skills of handwriting and spelling (McCutchen, 1996). Learning the mechanics of writing to a point of automaticity during primary school years frees the components of working memory for planning, generating, and reviewing (Graham, Berninger, Abbott, Abbott, \& Whitaker, 1997). Mastery of handwriting and spelling is also a necessary condition for writers to begin to develop the control of cognition, emotion, and behavior that is needed to sustain the production of texts (Graham \& Harris, 2000).

Third, advancement to the use of writing as a means of thinking, as well as language production, emerges only after a decade or so of writing experience. In late adolescence and young adulthood, writers move beyond merely telling the reader what the author knows (Bereiter \& Scardamalia, 1987). Mature adult authors transform their own ideas as a consequence of generating text and reviewing their ideas and text. They come to use writing as a way of thinking through matters and constructing new knowledge structures in long-term memory. Reviewing the text often triggers more planning that transforms the author's ideas about the topic. Reviewing can also trigger more language generation to reduce the difference between what the author means and what the text says at the moment.

Such knowledge transforming requires concurrent representations in working memory of the author's ideas and the text's meaning (Traxler \& Gernsbacher, 1992). It also requires the coordination of complex interactions among planning, generating, and reviewing. As McCutchen (1996) documented in her review of the literature, each of these basic processes is constrained by working memory limitations. The number and qualitative nature of processes that a writer can coordinate at once depend on attaining sufficient fluency with each process. Absent mastery of and cognitive control over planning, generation, and reviewing, writers appear to never move beyond knowledge telling.

Several factors no doubt underlie the development of cognitive control in writing. These include (1) the maturation of working memory throughout adolescence (Sowell, Thompson, Holmes, Jernigan, \& Toga, 1999), (2) learning strategies for prewriting, drafting, and revision that manage the demands of composition (Fayol, 1999), and (3) rapid retrieval of domain-specific knowledge from long-term memory when needed during composition, thus avoiding the need for transient storage in short-term working memory (Kellogg, 2001; McCutchen, 2000). However, the use of deliberate practice to reduce directly the working memory demands of each writing process offers an obvious and potentially valuable alternative that has yet to be fully realized in writing education.

\section{Deliberate Practice}

In our opinion, we must train college-level writers rather than merely instruct them. Knowledge of correct spelling, punctuation, grammar, diction, thesis statements, topic sentences and cohesive links within a paragraph, and global organization of texts are necessary but not sufficient for effective writing. Writers, just like musicians and athletes, must be trained, so that what they know is retrieved and creatively applied during composition (Kellogg, 1994). Effective use of knowledge will require that college students deliberately practice the craft of writing extended texts, in English composition courses and across the curriculum in all subjects. Without training to use what they know, their knowledge too often remains inert during composition.

A central factor in the development of expert performance across a wide range of both physical and cognitive task domains is the use of deliberate practice (K. A. Ericsson, 2006). For written composition, such practice could in theory reduce the intense working memory demands of planning, generating, and reviewing, thus freeing limited capacity for controlling and monitoring these operations. The effect of deliberate practice is not simply to automate a skill, but rather to enable its regulation to achieve superior performance (Zimmerman, 2006). This method of skill development involves (1) exertion to improve performance, (2) intrinsic motivation to engage in the task, (3) practice tasks within reach of the individual's ability, (4) feedback that provides knowledge of results, and (5) high levels of repetition over a period of several years.

Intrinsic motivation and evidence of high levels of repetition can be found in the reports of successful novelists. The prolific novelist Stephen King (2000) reported that when he is working on a book he writes 2,000 words every 
day of the year, including his birthday, Christmas, and the Fourth of July. Joyce Carol Oates deliberately practiced as a college student by writing a novel in longhand, then turning that novel's pages over and writing another novel on the flip side. Both novels would then be tossed in the trash. Since high school she began "consciously training myself by writing novel after novel and always throwing them out when I completed them" (Plimpton, 1989; p. 378). Norman Mailer (2003) also credited his eventual success as a writer to self-motivated practice.

I think from the time I was seventeen, I had no larger desire in life than to be a writer, and I wrote ... I learned to write by writing. As I once calculated, I must have written more than a half a million words before I came to The Naked and the Dead. (pp. 13-14)

According to the 10-year rule, it requires at least a decade of deliberate practice to become an expert in a given domain of skill (K. A. Ericsson et al., 1993) and this holds for written composition (Kellogg, 2006). An early study of scientists and authors showed that they achieved their best work in their mid-thirties, approximately a decade after their first work had been published (Raskin, 1936). Wishbow (1988) examined the biographies of 66 poets listed in the Norton Anthology of Poetry to determine approximately when they had started to read and write poetry. For $83 \%$ of the sample, the earliest published work to appear in Norton came 10 years after this date or later. Both poets and fiction writers developed mechanics and cognitive writing skills for 15-20 years before first publishing (Kaufman \& Gentile, 2002). Childhood story writing was so commonly mentioned in Henry's (2000; p. 37) ethnographies that "people who were attracted to writing after childhood may even refer to themselves as 'late bloomers."'

Practice can markedly improve college students' writing when it is done in the context of a professionally relevant task domain that motivates efforts to learn. Johnstone, Ashbaugh, and Warfield (2002) found that superior writing skills correlated reliably with the degree of repeated practice and, controlling for practice, with writing in the professionally relevant domain of greatest interest to the student. Accounting students who took two business writing intensive courses in their junior year (1 year of practice) and two more in their senior year (2 years of practice) gained significantly in their writing skills in comparison with an assessment taken at the end of their sophomore year (see Figure 1). In sharp contrast, the control group of students in other majors who did not take the writing intensive courses in their field slightly declined in performance from their sophomore to their senior year. The writing assignments in the treatment group were designed to challenge the students by requiring them to write as accounting professionals for a professional audience. The feedback that students received was consistent and thorough, including grading of grammatical conventions, organization, professionalism of presentation, technical accuracy of the accounting, and the quality of the analysis.

Deliberate practice would seem to lie at the core of the most effective educational interventions, judging from a

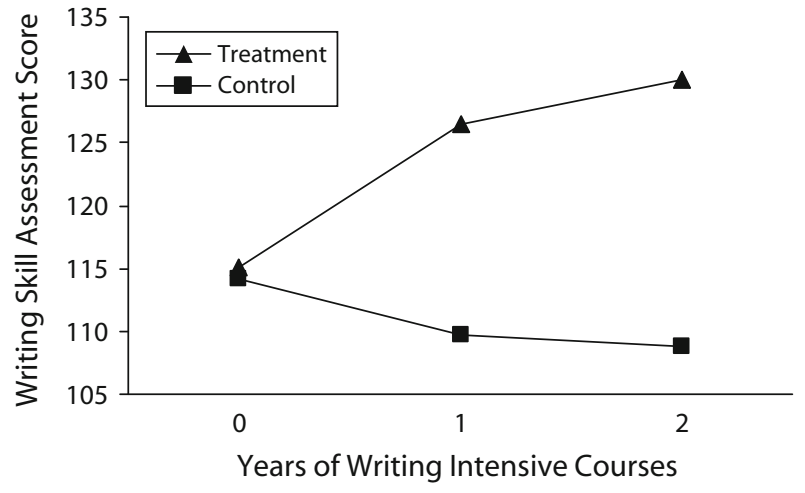

Figure 1. Mean writing skill assessment score as a function of practice in writing intensive courses (data from Johnstone, Ashbaugh, \& Warfield, 2002).

meta-analysis conducted by Hillocks $(1986,1995)$. He characterized the environmental mode of instruction in terms of several features consistent with deliberate practice. For example, such interventions require students to practice writing by assigning projects with clear objectives and well-structured problems. They use peer group responses to students' writing as a means to provide both relatively rapid feedback and a realistic context that engages and motivates students to succeed. The environmental mode actively trains students how to solve content and rhetorical problems, guides them to performance levels beyond what they could achieve on their own, and engages their interest by assigning writing tasks instead of having them listen to lectures. Hillocks's meta-analysis showed that the effect size of instruction in the environmental mode is more than four times larger than instruction in a presentational mode (traditional lectures, teacher presentations, and drills).

Astin (1993) measured self-reported gains in writing and other cognitive skills across the undergraduate years in college. Aside from GPA and hours spent studying, the two strongest partial correlations with writing skill improvement were the number of writing-skills classes taken $\left(\beta_{\mathrm{p}}=.31\right)$ and the amount of feedback given by instructors $\left(\beta_{\mathrm{p}}=.12\right)$.

\section{Problems With Practice}

We contend that deliberate practice should lie at the heart of writing education. This suggestion raises two important design problems, however. We conclude with a brief look at how to distribute practice over time and the difficulties of providing timely and useful feedback.

Spaced practice. Spacing practice, instead of blocking it into long sessions, is essential for two reasons. First, appropriately distributed practice is a desirable learning difficulty that promotes long-term retention and transfer of skills (Schmidt \& Bjork, 1992). A good example comes from teaching handwriting in elementary school, where, traditionally, students first write the letter "A" numerous times, then progress to "B" and so on. Sainte-Marie, Clark, Findlay, and Latimer (2004) found that letter repeti- 
tions performed in a random order greatly benefited the speed of later producing words in handwriting compared with the traditional blocked order. Because handwriting must first be mastered before executive attention can be allocated to higher order writing skills, the adoption of a spaced practice regimen in primary instruction would seem crucial.

Second, writing in marathon sessions is a kind of blocked practice that students and perhaps even some of their professors use to meet deadlines. Such writing binges can cause anxiety, exhaustion, and writer's block (Boice, 1985, 1997). Professional writers typically compose on a consistent schedule of a few hours per day at most (Kellogg, 2006). Such habits keep them in practice on an appropriately distributed schedule and prevent the negative consequences of excessively long writing sessions. Students should be explicitly trained to engage in distributed practice, as do professionals, to avoid exhaustion and sustain motivation. Self-recording of the time spent writing and the number of words generated in each session would be an effective way for the student and instructor to monitor progress (Zimmerman, 2006). Setting and achieving goals help to motivate the student. Such training ought to especially benefit students who are apprehensive about their writing abilities and have low expectations for success (Daly, 1985).

Timely and useful feedback. Deliberate practice requires that students be provided with knowledge of the results of their work. Such feedback is recognized as a powerful learning aid (see Metcalfe \& Kornell, 2007), but it poses special problems in the context of grading written texts. Although there are probably many reasons why more writing is not routinely assigned, the time and effort required by instructors to provide useful feedback surely ranks high on the list. Holistic grading can be done faster than analytic grading, which evaluates different features of the text, such as mechanics, coherence, and content (Huot, 1990). Yet even holistic grading can be excessively timeconsuming in large classes. The Center for Survey Research and Analysis (2002) found that 95\% of high school history teachers view writing a research term paper as important, but only $19 \%$ assign a paper of more than 5,000 words, because it takes too long to grade papers of such length. At research universities, grading of undergraduate writing is both laborious and too little rewarded by administrations that emphasize faculty publication and mentoring of graduate students. Perhaps the hard, unrewarded work of grading partly explains why writing across the curriculum programs and writing intensive courses reached their peak popularity about 20 years ago and have since been in decline at American universities (Bok, 2006).

An innovative contribution of cognitive science to boosting the amount of writing assigned and the timeliness of feedback is the recent development of automated essay scoring. Shermis and Burstein (2003) reviewed several computer-based scoring and feedback methods derived from cognitive psychology and computational linguistics. Students not only need far more opportunities to write, both in assigned papers and on tests; they also could benefit from the immediate knowledge of results that only software can provide. Computer-based feedback on preliminary drafts could motivate students to improve their scores before they turn in their papers for feedback from peers or instructors.

Early efforts at automatic scoring of objective text features relied on the readability formulas and tabulation of problems with spelling, grammar, and vocabulary (Macdonald, Frase, Gingrich, \& Keenan, 1982). They were limited in providing feedback regarding more complex, higher level features of writing quality, however. The promise of current software stems from success in the immediate scoring of essays in a way that parallels human graders. For example, the Educational Testing Service developed the e-rater system using text characteristics specified in holistic scoring guides for the Graduate Management Admissions Test (GMAT). The output of e-rater shows $87 \%-94 \%$ agreement with expert graders, a level similar to that of two well-trained human evaluators (Burstein, 2003). As another example, the Intelligent Essay Assessor uses latent semantic analysis to provide a holistic essay score that correlated .81 with a human grader averaged across many essays (Landauer, Laham, $\&$ Foltz, 2003). This was comparable to the correlation between two human raters (.83).

Some scholars in the field of college composition have strongly objected to the validity of automated essay scoring (P. F. Ericsson \& Haswell, 2006). Weighing their objections against the potential benefits is beyond our scope, but it should be noted that the reliability of human essay scoring is problematic, too. Human evaluators must be extensively trained to reach adequately high levels of reliability among raters. Fatigue, mood, and motivation add variability to the outcome in ways that are hard to control (Freedman \& Calfee, 1983).

We are not suggesting here that feedback must be provided for every assignment written, or that computer-based feedback can entirely substitute for feedback from human peers and instructors. Conceivably, intermittent feedback might serve as a desirable learning difficulty that harms acquisition performance but benefits long-term learning of writing skills (Schmidt \& Bjork, 1992). Moreover, a variety of feedback sources might be most useful to provide both correction of errors and encouragement to practice and improve. Still, automated essay scoring offers the potential to increase markedly the amount of writing assigned to students and the speed of receiving feedback.

\section{Conclusion}

Deliberate practice, we suggest, should be a fundamental principle that guides the instruction and training of student writers. As with the acquisition of other complex physical and cognitive skills, acquiring expertise in the writing of extended texts takes many years of deliberate practice. Presumably, such practice helps writers to gain cognitive control over text production by reducing the individual working memory demands of planning ideas, 
text generation, and reviewing ideas and text. A writer's ability to use linguistic and domain-specific knowledge in composing a text and in solving the content and rhetorical problems it poses depends on achieving such control.

That only $2 \%$ of high school seniors achieve an advanced score on the NAEP test of writing skill may be at least in part a consequence of insufficient or poorly designed practice. Research is needed, in our view, on the best ways to implement deliberate practice in educational interventions, including application of the spacing effect and advances in automated essay scoring. Such applied cognitive research has the potential for making significant improvements in writing education.

\section{AUTHOR NOTE}

Correspondence concerning this article should be addressed to R. T. Kellogg, Department of Psychology, Saint Louis University, 211 N. Grand Blvd., St. Louis, MO 63103 (e-mail: kelloggr@slu.edu).

\section{REFERENCES}

Astin, A. W. (1993). What matters in college?: Four critical years revisited. San Francisco: Jossey-Bass.

Benjamin, R., \& Chun, M. (2003). A new field of dreams: The Collegiate Learning Assessment Project. Peer Review, 5, 26-29.

Bereiter, C., \& Scardamalia, M. (1987). The psychology of written composition. Hillsdale, NJ: Erlbaum.

Borce, R. (1985). Cognitive components of blocking. Written Communication, 2, 91-104.

BoICE, R. (1997). Which is more productive, writing in binge patterns of creative illness or in moderation? Written Communication, 14 435-459.

BоK, D. (2006). Our underachieving colleges: A candid look at how much students learn and why they should be learning more. Princeton, NJ: Princeton University Press.

BrandT, D. (2005). Writing for a living: Literacy and the knowledge economy. Written Communication, 22, 166-197.

Burstein, J. (2003). The e-rater scoring engine: Automated essay scoring with natural language processing. In M. D. Shermis \& J. Burstein (Eds.), Automated essay scoring: A cross-disciplinary perspective (pp. 113-122). Hillsdale, NJ: Erlbaum.

Center for Survey Research and Analysis (2002, November). History research paper study. Retrieved December 15, 2003, from the Concord Review Web site: www.tcr.org/tcr/institute/historytcr.pdf.

DALY, J. A. (1985). Writing apprehension. In M. Rose (Ed.), When a writer can't write (pp. 43-82). New York: Guilford.

Duncan, J., Seitz, R. J., Kolodny, J., Bor, D., Herzog, H., Ahmed, A., ET AL. (2000). A neural basis for general intelligence. Science, $\mathbf{2 8 9}$ 457-460.

Engle, R. W., Tuholski, S. W., Laughlin, J. E., \& Conway, A. R. A. (1999). Working memory, short-term memory, and general fluid intelligence: A latent-variable approach. Journal of Experimental Psychology: General, 128, 309-331.

Ericsson, K. A. (2006). The influence of experience and deliberate practice on the development of superior expert performance. In K. A. Ericsson, N. Charness, P. J. Feltovich, \& R. R. Hoffman (Eds.), The Cambridge handbook of expertise and expert performance (pp. 683703). New York: Cambridge University Press.

Ericsson, K. A., Krampe, R. T., \& Tesch-Römer, C. (1993). The role of deliberate practice in the acquisition of expert performance. Psychological Review, 100, 363-406.

ERICSSON, P. F., \& HASWELl, R. H. (EDS.) (2006). Machine scoring of student essays: Truth and consequences. Logan, UT: Utah State University Press.

FAYOL, M. (1999). From on-line management problems to strategies in written composition. In M. Torrance \& G. Jeffery (Eds.), The cognitive demands of writing: Processing capacity and working memory effects in text production (pp. 13-23). Amsterdam: Amsterdam University Press.
Freedman, S. W., \& Calfee, R. C. (1983). Holistic assessment of writing: Experimental design and cognitive theory. In P. Mosenthal, L. Tamor, \& S. A. Walmsley (Eds.), Research on writing: Principles and methods (pp. 75-98). New York: Longman.

GeISER, S., \& STUDLEy, R. (2001). UC and the SAT: Predictive validity and differential impact of the SAT I and SAT II at the University of California. Retrieved March 1, 2002, from the University of California, Office of the President Web site: www.ucop.edu/sas/research/ researchandplanning/pdf/sat_study.pdf.

Graham, S., Berninger, V. W., Аввотt, R. D., Аввотt, S. P., \& WHITAKER, D. (1997). Role of mechanics in composing of elementary school students: A new methodological approach. Journal of Educational Psychology, 89, 170-182.

Graham, S., \& Harris, K. R. (2000). The role of self-regulation and transcription skills in writing and writing development. Educational Psychologist, 35, 3-12.

HAYES, J. R., \& FlOWER, L. S. (1980). Identifying the organization of writing processes. In L. W. Gregg \& E. R. Steinberg (Eds.), Cognitive processes in writing (pp. 3-30). Hillsdale, NJ: Erlbaum.

HAYES, J. R., \& Flower, L. S. (1986). Writing research and the writer. American Psychologist, 41, 1106-1113.

HENRY, J. (2000). Writing workplace cultures: An archeology of professional writing. Carbondale, IL: Southern Illinois University Press.

HILLOCKS, G., JR. (1986). Research on written composition: New directions for teaching. Urbana, IL: National Council on Research in English.

HILLOCKs, G., JR. (1995). Teaching writing as reflective practice. New York: Teachers College Press.

Huot, B. (1990). The literature of direct writing assessment: Major concerns and prevailing trends. Review of Educational Research, $\mathbf{6 0}$, 237-263.

Johnstone, K. M., Ashbaugh, H., \& Warfield, T. D. (2002). Effects of repeated practice and contextual-writing experiences on college students' writing skills. Journal of Educational Psychology, 94, 305-315.

Kaufman, J. C., \& Gentile, C. A. (2002). The will, the wit, the judgment: The importance of an early start in productive and successful creative writing. High Ability Studies, 13, 115-123.

KellogG, R. T. (1994). The psychology of writing. New York: Oxford University Press.

KellogG, R. T. (1996). A model of working memory in writing. In C. M. Levy \& S. E. Ransdell (Eds.), The science of writing: Theories, methods, individual differences, and applications (pp. 57-71). Mahwah, NJ: Erlbaum.

KeLlOGG, R. T. (2001). Long-term working memory in text production. Memory \& Cognition, 29, 43-52.

KellogG, R. T. (2006). Professional writing expertise. In K. A. Ericsson, N. Charness, P. J. Feltovich, \& R. R. Hoffman (Eds.), The Cambridge handbook of expertise and expert performance (pp. 389-402). New York: Cambridge University Press.

Kellogg, R. T., Olive, T., \& Piolat, A. (2007). Verbal, visual, and spatial working memory in written language production. Acta Psychologica, 124, 382-397.

KING, S. (2000). On writing: A memoir of the craft. New York: Scribner.

Landauer, T. K., Laham, D., \& Foltz, P. (2003). Automatic essay assessment. Assessment in Education, 10, 295-308.

LEVy, C. M. (1997). The "R" that psychology forgot: Research on writing processes. Behavior Research Methods, Instruments, \& Computers, 29, 137-145.

LEVy, C. M., \& RANSDELL, S. (1995). Is writing as difficult as it seems? Memory \& Cognition, 23, 767-779.

Macdonald, N. H., Frase, L. T., Gingrich, P. S., \& Keenan, S. A. (1982). The writer's workbench: Computer aids for text analysis. Educational Psychologist, 17, 172-179.

MaIler, N. (2003). The spooky art: Some thoughts on writing. New York: Random House.

McCutchen, D. (1984). Writing as a linguistic problem. Educational Psychologist, 19, 226-238.

McCutchen, D. (1996). A capacity theory of writing: Working memory in composition. Educational Psychology Review, 8, 299-325.

MCCUTCHEN, D. (2000). Knowledge, processing, and working memory: Implications for a theory of writing. Educational Psychologist, 35, $13-23$. 
Metcalfe, J., \& Kornell, N. (2007). Principles of cognitive science in education: The effects of generation, errors, and feedback. Psychonomic Bulletin \& Review, 14, 225-229.

National Assessment of Educational Progress (2002). The nation's report card. Writing 2002 major results. Retrieved September 23, 2003, from nces.ed.gov/nationsreportcard/writing/results2002/.

Nickerson, R. S., Perkins, D. N., \& Smith, E. E. (1985). The teaching of thinking. Hillsdale, NJ: Erlbaum.

Plimpton, G. (ED.) (1989). Women writers at work: The Paris Review interviews. New York: Penguin.

RANSDELL, S., \& LEVY, C. M. (1996). Working memory constraints on writing quality and fluency. In C. M. Levy \& S. E. Ransdell (Eds.), The science of writing: Theories, methods, individual differences, and applications (pp. 93-105). Mahwah, NJ: Erlbaum.

Ransdell, S., Levy, C. M., \& KellogG, R. T. (2002). The structure of writing processes as revealed by secondary task demands. $L-1: E d u$ cational Studies in Language \& Literature, 2, 141-163.

RASKIN, E. (1936). Comparison of scientific and literary ability: A biographical study of eminent scientists and men of letters of the nineteenth century. Journal of Abnormal \& Social Psychology, 31, 20-35.

Rijlaarsdam, G., Braaksma, M., Couzijn, M., Janssen, T., Kieft, M., BroekKamp, H., \& VAN DEN Bergh, H. (2005). Psychology and the teaching of writing in 8000 and some words. Pedagogy-Learning for Teaching, BJEP Monograph Series II, 3, 127-153.

Sainte-Marie, D. M., Clark, S. E., Findlay, L. C., \& Latimer, A. E. (2004). High levels of contextual interference enhance handwriting skill acquisition. Journal of Motor Behavior, 36, 115-126.
Scardamalia, M., \& Bereiter, C. (1991). Literate expertise. In K. A. Ericsson \& J. Smith (Eds.), Toward a general theory of expertise: Prospects and limits (pp. 172-194). Cambridge: Cambridge University Press.

SchmidT, R. A., \& BJork, R. A. (1992). New conceptualizations of practice: Common principles in three paradigms suggest new concepts for training. Psychological Science, 3, 207-217.

Shermis, M. D., \& Burstein, J. (2003). Automated essay scoring: A cross-disciplinary perspective. Hillsdale, NJ: Erlbaum.

Sowell, E. R., Thompson, P. M., Holmes, C. J., Jernigan, T. L., \& TogA, A. W. (1999). In vivo evidence for post-adolescent brain maturation in frontal and striatal regions. Nature Neuroscience, $\mathbf{2}$, 859-861.

Traxler, M. J., \& Gernsbacher, M. A. (1992). Improving written communication through minimal feedback. Language \& Cognitive Processes, 7, 1-22.

Wishbow, N. A. (1988). Studies of creativity in poets (Doctoral dissertation, Carnegie Mellon University, 1988). Dissertation Abstracts International, 51, 0491A.

Zimmerman, B. J. (2006). Development and adaptation of expertise: The role of self-regulatory processes and beliefs. In K. A. Ericsson, N. Charness, P. J. Feltovich, \& R. R. Hoffman (Eds.), The Cambridge handbook of expertise and expert performance (pp. 705-722). New York: Cambridge University Press.

Zimmerman, B. J., \& RisemberG, R. (1997). Becoming a self-regulated writer: A social cognitive perspective. Contemporary Educational Psychology, 22, 73-101. 